\title{
Potencial bioterapêutico dos probióticos nas parasitoses intestinais
}

\author{
Probiotics as potential biotherapeutic agents targeting intestinal parasites \\ Teresa Cristina Goulart de Oliveira - Sequeira ${ }^{\mathrm{I}}$ Cláudia Mello Ribeiro ${ }^{\mathrm{II}}$ \\ Maria Isabel Franchi Vasconcelos Gomes ${ }^{\text {III }}$
}

- REVISÃo BIBLIOGRÁFICA -

\section{RESUMO}

Probióticos são microrganismos vivos que, se administrados em quantidades adequadas, promovem benefícios à saúde do homem e dos animais. O crescente interesse nos probióticos fundamenta-se em estudos clínicos nos quais a administração desses organismos foi avaliada na prevenção e no tratamento de desordens intestinais e sistêmicas. Os potenciais mecanismos de ação desses microrganismos incluem a exclusão competitiva, a produção de metabólitos com atividade antimicrobiana e a modulação da resposta imune. Em algumas circunstâncias clínicas específicas, os benefícios produzidos por esses microrganismos foram amplamente documentados, enquanto que em outras os resultados são contraditórios. No presente artigo de revisão, os probióticos foram abordados considerando-se o potencial bioterapêutico desses microrganismos nas parasitoses intestinais.

Palavras-chave: probióticos, uso terapêutico, parasitas intestinais.

\section{ABSTRACT}

Probiotics are live microorganisms which, when administered in adequate amounts, beneficially affect the general health status of man and animal. The great interest in probiotic microganisms is based on evidences from clinical studies indicating benefits in the prevention or treatment of a broad spectrum of gastrointestinal and systemic disorders. The potential mechanisms by which probiotics beneficially affect health include strengthening of the intestinal barrier, modulation of the immune response, and antagonism of pathogens either by the production of antimicrobial compounds or through competition for mucosal binding sites. In some specific clinical circumstances, there is clear evidence of benefit whereas in others, the results are dubious and important questions remaining unanswered. The aim of this review article is to focus probiotics on their potential as biotherapeutic agents against intestinal parasites.

Key words: probiotics, therapeutic use; intestinal parasites.

\section{INTRODUÇÃO}

O trato gastrointestinal abriga uma complexa e dinâmica população de microrganismos, em sua maioria, bactérias, que constituem a microbiota intestinal. Algumas dessas bactérias são adquiridas no nascimento e colonizam o intestino permanentemente, sendo por isso denominadas de nativas, enquanto outras transitam apenas temporariamente pelo trato intestinal (ANDOH \& FUJIYAMA, 2006). Como essa microbiota desempenha importante papel no desenvolvimento e na manutenção da resposta imune intestinal (YAMANAKA et al., 2003), as investigações nessa área têm atraído muito interesse

IDepartamento de Parasitologia, Instituto de Biocências, Universidade Estadual Paulista Júlio de Mesquita Filho (UNESP), 18618000, Botucatu, SP, Brasil. E.mail: sequeira@ibb.unesp.br. Autor para correspondência.

IIDepartamento de Higiene Veterinária e Saúde Pública, Faculdade de Medicina Veterinária e Zootecnia (FMVZ), UNESP, Botucatu, SP, Brasil.

IIIDepartamento de Gestão e Tecnologia Agroindustrial, Faculdade de Ciências Agronômicas, UNESP, Botucatu, SP, Brasil. 
nos últimos anos. Um aspecto interessante diz respeito à possibilidade de se promover a manipulação terapêutica da microbiota intestinal para melhorar a saúde dos hospedeiros, pela administração de diversas espécies de microrganismos, coletivamente denominados de probióticos (ALANDER et al., 1999).

O termo probiótico foi utilizado pela primeira vez para designar substâncias secretadas por microrganismos, capazes de estimular o desenvolvimento de outros microrganismos (LILLY \& STILLWELL, 1965). Atualmente, nas várias definições disponíveis, nota-se uma maior preocupação em se enfatizar a atividade profilática ou mesmo terapêutica desses microrganismos (FIORAMONTI et al., 2003). Assim, probióticos podem ser definidos como sendo microrganismos vivos que, se administrados em quantidades adequadas, conferem benefícios à saúde do hospedeiro (SANDERS, 2003).

A maioria dos microrganismos probióticos são bactérias ácido-láticas, gram-positivas, geralmente catalase-negativas, que crescem em microaerofilia. Assim sendo, os probióticos incluem espécies ácidoláticas dos gêneros Lactobacillus, Bifidobacterium, Enterococcus, Lactococcus, Leuconostoc, Pediococcus, Sporolactobacillus e Streptococcus; espécies não ácido-láticas, tais como, Bacillus cereus, Escherichia coli e Propionibacterium freudenreichii; e as leveduras Saccharomyces cerevisiae e Saccharomyces boulardii (HOLZAPFEL et al., 2001). $\mathrm{Na}$ presente revisão, diferentes utilizações dos probióticos foram abordadas com o objetivo de divisar o potencial bioterapêutico desses microrganismos nas parasitoses intestinais.

Utilizações terapêuticas dos probióticos

Muitos experimentos clínicos têm sido conduzidos com o intuito de avaliar os efeitos dos probióticos na prevenção e no tratamento de desordens gastrintestinais causadas por microrganismos patogênicos ou pelos distúrbios da microbiota normal. Com isso, acumularam-se evidências sugestivas de que o consumo de probióticos está relacionado à melhoria de uma grande variedade de indicadores de saúde e bem-estar, e de que esses benefícios seriam mediados por um ou mais mecanismos. Entre os possíveis mecanismos de ação dos probióticos, destacam-se a competição com patógenos por receptores celulares (ZÁRATE \& NADER-MACIAS, 2006), a indução de secreção de mucina (MACK et al., 2003) e a modulação da resposta imunológica (PATURI et al., 2007).

Muitos dos benefícios proporcionados pela administração de probióticos são atribuídos à possibilidade dessas bactérias interferirem na resposta imune intestinal e na resposta sistêmica (FOLIGNE et al., 2007). Um exemplo disso foi obtido pela constatação de que a administração de Lactobacillus rhamnosus GG mostrou-se segura e eficaz no tratamento de alergias alimentares (MAJAMAA \& ISOLAURI, 1997) e de eczema atópico (ISOLAURI et al., 2000). Além disso, quando administrados às gestantes, no período prénatal, esses lactobacilos foram efetivos na prevenção de atopias em crianças consideradas de alto risco (KALLIOMÄKI et al., 2001).

A prescrição de probióticos tem sido amplamente investigada no tratamento ou na prevenção de infecções intestinais, particularmente, as provocadas por vírus (rotavírus), Clostridium difficile, outras espécies de bactérias causadoras de enterites (Escherichia coli, Salmonela etc.) e de enterites inespecíficas, como a diarréia dos viajantes (GIONCHETTI et al., 2002). Resultados de estudos clínicos demonstraram que bactérias acidolácticas, tais como L. rhamnosus GG, apresentam efeitos positivos no tratamento de gastrenterites por rotavírus em crianças (SALMINEN et al., 2005). Utilizando ensaios in vitro, foi possível verificar que algumas espécies de probióticos, notadamente Lactobacillus e Bifidobacterium, induzem os macrófagos a produzir citocinas inibidoras da replicação viral (IVEC et al., 2007), o que explica em parte a atividade dessas bactérias no tratamento das gastrenterites virais.

Nas gastrenterites bacterianas, os principais mecanismos pelos quais os probióticos exercem sua ação benéfica incluem a exclusão competitiva (por nutrientes ou sítios de adesão) e a excreção/secreção de substâncias antimicrobianas (bacteriocinas). Dessa forma, há relatos de que algumas cepas de Lactobacillus são capazes de inibir in vitro a adesão de Escherichia coli enteropatogênica aos enterócitos de suínos (SPENCER \& CHESSON, 1994) e de Clostridium perfringens e de Campylobacter jejuni ao muco intestinal de cães (RINKINEN et al., 2003).

A utilização de probióticos também tem sido considerada uma alternativa plausível no controle de infecções fora do trato gastrintestinal. Há estudos que demonstram que algumas cepas selecionadas de Lactobacillus (L. rhamnosus GR-1 e L. reuteri B-54 e RC-14) podem reduzir a recorrência de infecções do trato urinário e o risco de vaginites (REID et al., 2004; REID \& BRUCE, 2006).

No que se refere aos processos neoplásicos, tem-se verificado que cepas de Lactobacillus apresentam atividade antitumoral em modelos experimentais (ASANO et al., 1986). A partir desses estudos experimentais, nos quais se verificou que os probióticos eram capazes de prevenir o surgimento de 
lesões pré-neoplásicas (focos de criptas aberrantes) e danos ao DNA no cólon de ratos, esses microrganismos foram utilizados em testes clínicos em seres humanos. No primeiro ensaio duplo-cego realizado com portadores de câncer polipectomizados (RAFTER et al., 2007), constatou-se que a administração de probióticos (Bifidobacterium lactis Bb12 e Lactobacillus delbreuckii rhamnosus GG), em associação com prebióticos, produziu alterações favoráveis em vários biomarcadores de câncer coloretal. Esta pode ser uma das explicações para a constatação de que, nas populações que têm o hábito de consumir grandes quantidades de produtos lácteos contendo Lactobacillus ou Bifidobacterium, a incidência de câncer de cólon é mais baixa. Também seria essa uma razão pela qual o consumo regular de leite fermentado contendo o probiótico $L$. casei foi considerado responsável pela diminuição da recorrência de câncer superficial de bexiga (ASO et al., 1995; OHASHI et al., 2002).

Utilização de probióticos como promotores de crescimento

Atualmente, as pesquisas com probióticos têm sido impulsionadas por duas forças complementares. De um lado, a demanda crescente por métodos mais conservacionistas para o tratamento e a prevenção de infecções, fruto da maior conscientização ecológica da população leiga. De outro, a preocupação da comunidade científica com o surgimento de cepas de microrganismos resistentes e com o uso indiscriminado de agentes antimicrobianos. Em função disso, uma área que tem se mostrado bastante promissora é a da utilização de probióticos como promotores de crescimento e de sanidade de animais de produção, em substituição às doses subterapêuticas de antibióticos, comumente utilizadas nas rações de animais criados intensivamente, como aves e suínos (GUERRA et al., 2007).

Na União Européia, onde desde janeiro de 2006 está proibida a utilização de antibióticos como promotores de crescimento em animais de produção (MISSOTTEN et al., 2007), os estudos sobre a utilização de bactérias se intensificaram revelando que sua administração aos suínos constitui uma forma ecológica de se obter resultados semelhantes aos produzidos pela administração de antibióticos (DAVIS et al., 2007).

A adição de quimioterápicos antimicrobianos na ração de aves de corte e de postura é considerada uma prática eficaz, tendo sido amplamente utilizada no Brasil e em diversas partes do mundo. No entanto, a presença de resíduos na carne e nos ovos e sua associação com a indução cruzada de resistência a antibióticos em bactérias patogênicas e a ocorrência de casos de reações de hipersensibilidade e de câncer motivaram uma pressão social para a interrupção dessa prática (FARIA-FILHO et al., 2006). Assim, as pesquisas sobre formas alternativas para incrementar a produtividade das aves têm sido consideradas uma prioridade, principalmente, no que se refere à utilização de probióticos (EDENS, 2003).

Potencial terapêutico dos probióticos nas parasitoses intestinais

No que diz respeito às infecções por parasitas intestinais, uma indicação da possibilidade de se utilizar probióticos na prevenção e/ou no controle adveio da observação de que a microbiota intestinal interfere na colonização do intestino de camundongos isogênicos por Giardia duodenalis (= Giardia lamblia) (SINGER \& NASH, 2000). A partir dessas observações, passou-se a investigar a atividade de bactérias probióticas contra Giardia, utilizando ensaios in vitro e in vivo. Assim, ao investigarem os efeitos de oito cepas de Lactobacillus sobre trofozoítas de cultura de Giardia, PÉREZ et al. (2001), constataram que, no sobrenadante de cultura de duas dessas cepas, havia substâncias que inibiam significativamente a proliferação de trofozoítas.

Nos ensaios in vivo, a administração prévia de L. johnsonii La1 a gerbilíneos (Meriones unguiculatus) também se revelou capaz de reduzir a taxa de infecção dos animais e a excreção de antígenos de Giardia nas fezes (HUMEN et al., 2005). Outra evidência da proteção conferida pelo probiótico foi a preservação da integridade histológica da mucosa intestinal e de marcadores enzimáticos no intestino dos animais tratados. Os resultados desse primeiro ensaio in vivo para avaliar o efeito de bactérias probióticas na giardíase foram interpretados como sendo uma evidência científica de que os probióticos podem constituir uma alternativa na prevenção dessa parasitose.

Nos ensaios em que outro lactobacilo (Enterococcus faecium SF68) foi administrado a camundongos (BENYACOUB et al., 2005), os animais tratados apresentaram resposta imune específica antiGiardia mais efetiva, caracterizada por níveis mais elevados de anticorpos IgA no intestino, de IgG no soro e por maior número de linfócitos T-CD4 ${ }^{+}$nas placas de Peyer. Esses animais apresentaram também número significativamente menor de trofozoítas no intestino e menor quantidade de antígenos de Giardia. A rápida eliminação dos trofozoítas e de antígenos de Giardia, concomitantemente à intensificação da resposta imunológica nos camundongos tratados, foi 
interpretada como sendo mais um reforço à idéia de se empregar probióticos como Enterococcus faecium SF68 no tratamento de infecções por Giardia.

Atualmente, as drogas disponíveis para o tratamento da giardíase incluem derivados de nitroimidazóis e nitrofuranos, tais como metronidazol, tinidazol, furazolidona e albendazol (HUMEN et al., 2005). No entanto, de acordo com WRIGHT et al. (2003), os registros clínicos e laboratoriais de resistência contra essas drogas reforçam a necessidade de se identificar novos agentes contra a giardíase e alternativas que preservem a viabilidade das drogas existentes.

Os ensaios clínicos para avaliação dos probióticos na giardíase são ainda bastante escassos. Em Cuba, GUILLOT et al. (1995) realizaram um ensaio duplo-cego no qual a levedura Saccharomyces boulardii foi administrada a crianças que haviam sido curadas da infecção por Giardia com tratamento específico (Tinidazol), mas que continuaram apresentando diarréia. Esses autores verificaram que nessa situação (síndrome pós-gastrenterite) a administração de $\boldsymbol{S}$. boulardii (250mg, duas vezes ao dia durante 30 dias) produziu melhora significativa no quadro clínico e nas avaliações histopatológicas do intestino das crianças tratadas. Além da redução da diarréia, verificou-se que a administração do probiótico proporcionou uma rápida recuperação da mucosa jejunal, tendo por base a avaliação histológica anterior e posterior ao tratamento.

Em Ancara, Turquia, BESIRBELLIOGLU et al. (2006) avaliaram o efeito da administração de probióticos em associação com metronidazol, droga de escolha para o tratamento da giardíase. Nesse ensaio duplo-cego, um grupo de pessoas infectadas com Giardia recebeu metronidazol em associação com $\boldsymbol{S}$. boulardii e outro (grupo placebo), exclusivamente com metronidazol. Na avaliação para controle de cura, cistos de Giardia foram encontrados apenas em indivíduos do grupo placebo, indicando que a associação de $\boldsymbol{S}$. boulardii ao metronidazol foi mais eficaz no tratamento da giardíase.

De acordo com ALI \& NOZAKI(2007), os protozoários amitocondriados, como é o caso de Giardia duodenalis e Entamoeba histolytica, apresentam várias características bioquímicas comuns, inclusive a susceptibilidade ao mesmo espectro de drogas e a possibilidade de desenvolvimento de resistência. Esta pode ser a razão pela qual a associação da levedura $\boldsymbol{S}$. boulardii ao tratamento convencional para $\boldsymbol{E}$. histolytica tenha produzido resultados semelhantes aos relatados para Giardia. Utilizando ensaio duplo-cego, MANSOUR-GHANAEI et al. (2003) associaram a levedura $\boldsymbol{S}$. boulardii ao metronidazol e iodoquinol para o tratamento da disenteria amebiana aguda. Nos pacientes que receberam a levedura além das drogas convencionais, a duração da diarréia, da febre, da dor abdominal e da eliminação de cistos foi significativamente menor que nos pacientes que receberam apenas o tratamento convencional.

Ao que tudo indica, a expressão do efeito antagonista dos probióticos nas infecções por Giardia e Entamoeba deve ser multifatorial, já que um determinado mecanismo relevante na inibição de um desses patógenos pode não ter relevância para outro. A inibição da adesão de trofozoítas de $\boldsymbol{E}$. histolytica foi o principal mecanismo antagonista verificado em ensaios nos quais os trofozoítas foram previamente expostos à suspensão de $\boldsymbol{S}$. boulardii (RIGOTHIER et al., 1994). Por outro lado, nos ensaios em que trofozoítas de Giardia foram expostos a $\boldsymbol{L}$. johnsonii La1 (PÉREZ et al., 2001), a inibição da proliferação do protozoário foi atribuída aos efeitos citopáticos do probiótico, já que não houve interferência no processo de adesão dos trofozoítas.

O papel da microbiota intestinal na proteção contra parasitas intestinais não se restringe aos protozoários que vivem na luz intestinal, sendo também reconhecido no caso de protozoários intracelulares. Assim, verificou-se que camundongos "germ-free", recém nascidos ou adultos, são mais susceptíveis às infecções por Cryptosporidium que camundongos adultos convencionais, cujas microbiotas já estão estabelecidas (HARP et al., 1988; HARP et al., 1992). De acordo com HARP (2003), a atuação da microbiota intestinal na expressão de maior resistência poderia estar relacionada às seguintes possibilidades: bloqueio de receptores específicos do parasita pela simples presença física das bactérias no intestino, produção de substâncias pelas bactérias que seriam tóxicas para Cryptosporidium ou estimulação de algum componente do sistema imunológico pelas bactérias, aumentando a resistência contra esse parasita.

Cryptosporidium é reconhecido como importante causa de diarréia em seres humanos e em algumas espécies animais. Em indivíduos imunocompetentes, a criptosporidiose é autolimitante, mas constitui uma grave e persistente infecção oportunista em indivíduos imunocomprometidos, para a qual não existe terapia confiável (YARLETT et al., 2007). Embora seja inquestionável o papel da resposta imune no controle de infecções por Cryptosporidium, estudos realizados com camundongos portadores de Imunodeficiência Severa Combinada (SCID) revelaram que a presença da microbiota intestinal é capaz de mediar a resistência às infecções por esse parasita, mesmo na ausência de resposta imune específica (HARP et al., 1992).

À semelhança das constatações obtidas com outros agentes patogênicos, as pesquisas sobre 
os efeitos de probióticos nas infecções por Cryptosporidium têm demonstrado o envolvimento de diferentes mecanismos de ação e a ocorrência de resultados discrepantes, que se deve, em muitos casos, à espécie ou mesmo à linhagem da bactéria probiótica utilizada. Essas constatações têm sido produzidas tanto em ensaios in vivo (ALAK et al., 1999) como in vitro(FOSTER et al,. 2003).

ALAK et al. (1999) avaliaram o efeito da administração de $\boldsymbol{L}$. acidophilus e de $\boldsymbol{L}$. reuteri sobre a infecção por Cryptosporidium em camundongos isogênicos imunossuprimidos, usando como parâmetro de comparação a excreção de oocistos. Ambas as espécies de Lactobacillus promoveram a diminuição da excreção de oocistos pelos camundongos, sendo mais expressiva no caso de $\mathbf{L}$. acidophilus. Os autores postularam que a diminuição na produção de oocistos poderia estar associada à presença de substâncias liberadas pelas bactérias probióticas no lume intestinal. Posteriormente, avaliou-se o efeito do sobrenadante de cultura de duas espécies de Lactobacillus (L. acidophilus e $\mathbf{L}$. reuteri) e duas de Bifidobacterium (B. breve e B. longum) sobre a viabilidade in vitro de oocistos de Cryptosporidium parvum (FOSTER et al., 2003). Substâncias capazes de reduzir significativamente a viabilidade dos oocistos de Cryptosporidium foram produzidas por ambas as espécies de Lactobacillus. Quanto às espécies de Bifidobacterium, apenas $\boldsymbol{B}$. longum apresentou essa atividade, porém em menor intensidade. Posteriormente, esse grupo de pesquisadores (GLASS et al., 2004) constataram que as substâncias presentes no sobrenadante de culturas de $\boldsymbol{L}$. acidophilus e $\boldsymbol{L}$. reuteri eram capazes de reduzir a infectividade de oocistos de outras duas espécies de Cryptosporidium: $\boldsymbol{C}$. parvum isolado de bovinos e $\boldsymbol{C}$. hominis isolado de seres humanos.

O fato de a infecção por Cryptosporium ser autolimitante em indivíduos imunocompetentes e os animais adultos serem refratários (HARP et al., 1992) limita as possibilidades da modelagem experimental nessa infecção. Por isso, os efeitos da administração de probióticos sobre as infecções por Cryptosporidium têm sido avaliados em animais imunossuprimidos artificialmente (ALAK et al., 1997), animais portadores de mutações genéticas (WATERS et al., 1999) ou animais recém-nascidos (GUITARD et al.,2006).

Camundongos imunossuprimidos pelo vírus da leucemia murina e infectados com $\boldsymbol{C}$. parvum de origem bovina foram utilizados em ensaio com Lactobacillus reuteri (ALAK et al., 1997). Os autores constataram que os animais suplementados com o probiótico eliminaram o parasita do epitélio intestinal, enquanto os animais não-suplementados persistiam infectados e eliminando oocistos nas fezes. Verificaram também que à medida que se intensificava a colonização intestinal pelo lactobacilo, decrescia a eliminação de oocistos.

Nos ensaios realizados por WATERS et al. (1999), o efeito da administração de $\boldsymbol{L}$. reuteri foi avaliado em camundongos geneticamente modificados (TCR- $\alpha$ deficiente). Esses animais não possuem linfócitos $\alpha \beta \mathrm{T}$ e por isso persistem cronicamente infectados com $\boldsymbol{C}$. parvum. A administração de $\boldsymbol{L}$. reuteri minimizou a intensidade da reação inflamatória e, como conseqüência, a gravidade das infecções. No que diz respeito especificamente a $L$. reuteri, constatou-se um aumento na excreção de reuterina (3hidroxipropionaldeído), metabólito que apresenta atividade antimicrobiana sobre diversos microrganismos patogênicos. De acordo com ALAK et al. (1997), a atividade inibitória da reuterina sobre Cryptosporidium seria um possível mecanismo de ação desse probiótico.

Os efeitos de probióticos comerciais à base de lactobacilos foram avaliados em ratos neonatos infectados por C. parvum (genótipo 2). Diferentemente dos resultados anteriores, não houve diferença nos parâmetros como ganho de peso, carga parasitária, alterações histológicas da mucosa intestinal e produção de citocinas de animais suplementados, em relação aos não-suplementados com probióticos (GUITARD et al., 2006). No caso de Cryptosporidium, essas discrepâncias de resultados são particularmente difíceis de serem analisadas, pois a quantidade de dados disponíveis é pequena, os resultados foram obtidos em experimentos envolvendo diferentes espécies ou categorias de animais experimentais e de bactérias probióticas e foram empregados distintos protocolos para a administração dos probióticos. Além disso, atualmente, são admitidas várias espécies e vários genótipos de Cryptosporidium, morfologicamente indistinguíveis de $\boldsymbol{C}$. parvum, cuja identificação genotípica é importante, inclusive para se avaliar as possibilidades de controle (ABE et al., 2006).

Diante dessas considerações, torna-se clara a necessidade de novas pesquisas na busca de alternativas para a profilaxia e terapêutica da criptosporidiose, uma zoonose em expansão para a qual não existe tratamento eficaz. Nesse aspecto, merece destaque o único relato de emprego bem-sucedido de probióticos no tratamento da criptosporidiose humana (PICKERD \& TUTHILL, 2004). No caso em questão, a administração de dois produtos comerciais contendo lactobacilos a uma criança infectada com 
Cryptosporidium foi considerada responsável tanto pela remissão dos sintomas como pela resolução da infecção.

Diferentemente do que ocorre na criptosporidiose, as motivações para o desenvolvimento de métodos de controle alternativos para a coccidiose das aves incluem o desenvolvimento de resistência desses protozoários às drogas anticoccidianas disponíveis (WILLIAMS, 2006) e a rejeição da população à presença de resíduos na carne das aves. No caso das aves comerciais, diversos produtos contendo probióticos são disponíveis comercialmente, graças aos numerosos estudos que demonstraram os benefícios da administração desses produtos no desenvolvimento e na prevenção de doenças desses animais. No entanto, ainda são poucos os estudos dedicados a investigar, especificamente, os efeitos desses microrganismos na coccidiose aviária (DALLOUL \& LILLEHOJ, 2005).

A investigação da ação de um probiótico alimentar comercial à base de Lactobacillus (Primalac ${ }^{\circledR}$, Star-Labs, Inc.) na coccidiose por Eimeria acervulina, em frangos de corte, revelou que os animais tratados apresentaram aumento significativo do número de linfócitos intra-epiteliais que expressavam marcadores para CD3, CD4, CD8 e aßTCR e diminuição na excreção de oocistos na ordem de 75\% (DALLOUL et al., 2003a). $\mathrm{O}$ aumento do número de células $\mathrm{T}$, associado à posterior diminuição da excreção de oocistos, foi interpretado como sendo uma clara evidência de indução de maior resistência a esse coccídio.

Resultados similares foram obtidos em investigações nas quais os efeitos do probiótico $\left(\right.$ Primalac $^{\circledR}$ ) nas infecções por $\boldsymbol{E}$. acervulina foram analisados em frangos submetidos a uma dieta deficiente em vitamina A(DALLOUL et al., 2003b). Nas aves que receberam ração deficiente em vitamina $\mathrm{A}$, a excreção de oocistos foi $40 \%$ maior que a de aves alimentadas com ração normal. No entanto, a administração de probióticos proporcionou uma redução significativa na excreção de oocistos tanto nos animais que receberam dieta normal como nos submetidos à dieta deficiente em vitamina $\mathrm{A}$. Os autores concluíram que probióticos à base de Lactobacillus exercem ação estimuladora da resposta imune de aves, inclusive em situações em que ocorre comprometimento nutricional.

Em investigações subseqüentes (DALLOUL et al., 2005), os efeitos desse probiótico na resposta imune contra $\boldsymbol{E}$. acervulina foram comprovados pela exacerbação da resposta imune celular e pela maior resistência à infecção das aves tratadas. No entanto, o efeito protetor (14\% de redução na excreção de oocistos) foi considerado significativamente inferior aos obtidos nos ensaios anteriores. Os autores relacionaram essa menor atividade ao fato de as aves terem sido inoculadas com uma dose duas vezes maior de oocistos de $\boldsymbol{E}$. acervulina. A influência da dose de oocistos sobre o grau de proteção conferido pela administração de próbióticos foi também constatada recentemente por LEE et al. (2007). Os autores investigaram o efeito da administração de um probiótico comercial à base de Pediococcus acidilactici (MitoGrow, Imagilin Technology LLC) em infecções experimentais por $\boldsymbol{E}$. acervulina e E. tenella, nas quais as aves foram inoculadas com 5.000 ou 10.000 oocistos. Nos animais inoculados com E. tenella, a maior produção de anticorpos específicos nos animais suplementados com probióticos não se traduziu em aumento significativo do ganho de peso ou em redução da excreção de oocistos. No entanto, nas infecções por $\boldsymbol{E}$. acervulina, além do ganho de peso ter sido significativamente maior, a redução da excreção de oocistos foi constatada, especialmente, nos animais desafiados com 5.000 oocistos. Nesse trabalho, os autores consideraram que o maior ganho de peso dos animais suplementados com probióticos foi uma evidência indireta de que a administração de $\boldsymbol{P}$. acidilactici promove um aumento da resistência à coccidiose, já que a mais proeminente manifestação da coccidiose aviária é o retardo no crescimento.

Nas infecções por helmintos parasitas intestinais, os mecanismos pelos quais os probióticos exercem seus efeitos benéficos não são totalmente conhecidos, mas um dos mecanismos provavelmente envolvidos é a estimulação da resposta imune nãoespecífica. As primeiras indicações dessa possibilidade advêm de observações obtidas com a estimulação por outras bactérias não-probióticas. Pesquisas realizadas no Brasil (BARRETO et al., 2000) e em outros países (LIPNER et al., 2006) revelam que a incidência, prevalência e intensidade de infecção por ancilostomídeos são menores em crianças vacinadas com BCG (Bacilo-Calmette-Guerin) que nas nãovacinadas. Corroborando essas observações, ensaios in vivo realizados com camundongos experimentalmente infectados com Schistosoma mansoni (TEIXEIRA et al., 1996) mostraram que o número de vermes adultos recuperados de animais previamente inoculados com Corynebacteriun parvum era menor que o dos animais controles e também dos que foram inoculados com a bactéria após a infecção pelo verme.

No caso de bactérias probióticas, além do envolvimento de processos imunológicos 
inespecíficos, mecanismos não-imunológicos, como os relacionados às mucinas, têm recebido bastante atenção pela possibilidade de estarem implicados no fenômeno de expulsão dos vermes. As mucinas, camada de glicoproteínas que recobre a superfície do epitélio intestinal, além de constituírem uma barreira física entre o epitélio e o conteúdo do lume intestinal, exercem ação protetora contra patógenos intestinais através de diversos mecanismos. De acordo com GILL (2003), probióticos administrados oralmente podem afetar negativamente o estabelecimento e o desenvolvimento de patógenos como Nippostrongylus brasiliensis e Trichinella spiralis por interferir na regulação da expressão gênica das mucinas e na composição e excreção de muco.

Apesar dessas possibilidades, os dados disponíveis sobre os efeitos da administração de probióticos no curso das infecções por helmintos intestinais são escassos e restritos a poucas espécies de parasitas. O efeito da administração oral da bactéria Zymomonas mobilis na infecção experimental de camundongos por Schistosoma mansoni revelou que os animais que receberam a bactéria após a infecção pelo verme (tratamento curativo) tiveram uma redução na carga parasitária de 61\% em comparação com o grupo controle. Naqueles em que a bactéria foi administrada antes da infecção pelo verme (tratamento preventivo), a redução foi de apenas 24\% (SANTOS et al., 2004).

A expulsão de larvas de quarto estágio de Ascaris suum do jejuno de leitões suplementados com probiótico foi um dos efeitos positivos da administração de Bifidobacterium lactis (SOLANO-AGUIAR et al., 2004). Outra constatação foi o melhor desempenho na absorção de nutrientes pelos animais suplementados com o probiótico.

Uma significativa redução no número de adultos de Trichinella spiralis também foi observada em ensaios in vivo em que Lactobacillus casei foi administrado a camundongos por via intraperitoneal (BAUTISTA-GARFIAS et al., 1999). Além da redução do número de vermes, os animais tratados apresentaram maior infiltração de células mononucleares, menor número de mastócitos na mucosa e não apresentaram encurtamento das vilosidades intestinais. Em um segundo experimento, lactobacilos vivos ou mortos ou sobrenadante de cultura foram administrados por via oral a camundongos experimentalmente infectados (BAUTISTA-GARFIAS et al., 2001). A redução da carga parasitária foi mais expressiva nos animais que receberam lactobacilos vivos, porém, nos que receberam lactobacilos mortos ou sobrenadante de cultura, o número de vermes recuperados foi inferior ao dos animais controles.

Camundongos infectados com Trichinella spiralis também têm sido utilizados como modelo experimental para o estudo da atividade de probióticos sobre uma desordem intestinal de etiologia indefinida denominada de síndrome do intestino irritável. Nesses estudos, parâmetros especificamente relacionados aos aspectos parasitológicos da infecção, como redução de carga parasitária, não constituem objeto de análise. No entanto, uma das constatações obtidas nesses estudos (MARTIN et al., 2006) foi a de que animais infectados com Trichinella e tratados com probióticos apresentaram parâmetros metabólicos semelhantes aos de animais não-infectados, indicando que os probióticos promoveram uma parcial normalização das atividades metabólicas em animais infectados e tratados. Esses resultados são uma evidência de que os probióticos podem exercer seus efeitos benéficos nas helmintoses intestinais se não por aumentar a resistência dos hospedeiros (baixa carga parasitária), por contribuir para com a resilência (manutenção da saúde e produtividade) dos animais infectados.

\section{CONCLUSÕES}

O tratamento das parasitoses intestinais não sofreu alterações substanciais nos últimos 20 anos, de forma que atualmente é consensual entre os parasitologistas que o paradigma do controle baseado em drogas necessita ser alterado, de forma a que se evolua de um máximo de dependência de produtos químicos para um estágio de controle compatível com a sustentabilidade.

Nos países em desenvolvimento, o parasitismo intestinal por diferentes espécies de protozoários e helmintos persiste como um sério problema de Saúde Pública, principalmente pela constância com que se encontra associado à desnutrição, afetando com isso o desenvolvimento físico, cognitivo e social, especialmente das crianças. Nessa situação, a utilização de probióticos sob a forma de alimento funcional constitui uma alternativa sedutora por, em tese, possibilitar abordar conjuntamente os dois agravos. No entanto, tanto a seleção racional de bactérias probióticas como a sua incorporação a produtos alimentícios permanece como um desafio para a comunidade científica.

No que se refere aos animais domésticos, a utilização terapêutica dos probióticos parece bastante promissora, no entanto, estudos mais aprofundados são necessários a fim de se estabelecer a relevância dessas terapias em cada situação específica. A compreensão das bases moleculares dos mecanismos de ação desses microrganismos é um pré-requisito tanto para o desenvolvimento racional dos probióticos 
como para o respaldo do uso terapêutico desses produtos.

\section{REFERÊNCIAS}

ABE, N. et al. Subgenotype analysis of Cryptosporidium parvum isolates from humans and animals in Japan using the $60-\mathrm{kDa}$ glycoprotein gene sequences. Parasitology Research, v.99, n.3, p.303-305, 2006.

ALAK, J.I. et al. Supplementation with Lactobacillus reuteri or $\boldsymbol{L}$. acidophilus reduced intestinal shedding of Cryptosporidium parvum oocysts in immunodeficient C57BL/6 mice. Cellular and molecular biology, v.45, n.6, p.855-863, 1999.

ALAK, J.I. et al. Effect of Lactobacillus reuteri on intestinal resistance to Cryptosporidium parvum infection in a murine model of acquired immunodeficiency syndrome. Journal of Infectious Diseases, v.175, n.1, p.218-221, 1997.

ALANDER, M. et al. The effect of probiotic strains on the microbiota of the simulator of the human intestinal microbial ecosystem (SHIME). International Journal of Food Microbiology, v.46, n.1, p.71-79, 1999.

ALI, V.; NOZAKI, T. Current therapeutics, their problems, and sulfur-containing-amino-acid metabolism as a novel target against infections by "amitochondriate" protozoan parasites. Clinical microbiology reviews, v.20, n.1, p.164-187, 2007.

ANDOH, A.; FUJIYAMA, F. Therapeutic approaches targeting intestinal microflora in inflammatory bowel disease. World Journal of Gastroenterology, v.12, n.28, p.4452-4460, 2006.

ASANO, M. et al. T. Antitumor activity of Lactobacillus casei (LC 9018) against experimental mouse bladder tumor (MBT2). The Journal of Urology, v.136, n.3, p.719-721, 1986.

ASO, Y. et al. Preventive effect of a Lactobacillus case preparation on the recurrence of superficial bladder cancer in a double-blind trial. The BLP Study Group. European Urololgy, v.27, n.2, p.104-109, 1995.

BARRETO, M.L. et al. Lower hookworm incidence, prevalence and intensity of infection in children with a bacillus CalmetteGuerin vaccination scar. Journal of Infectious Diseases, v.182, n.6, p.1800-1803, 2000.

BAUTISTA-GARFIAS, C.R. et al. Effect of viable or dead Lactobacillus casei organisms administered orally to mice on resistance against Trichinella spiralis infection. Parasite, v.8, n.2, p.226S-228S, 2001.

BAUTISTA-GARFIAS, C.R. et al. Enhancement of resistance in mice treated with Lactobacillus casei: effect on Trichinella spiralis infection. Veterinary Parasitology, v.80, n.3, p.251260, 1999.

BENYACOUB, J. et al. Enterococcus faecium SF68 enhances the immune response to Giardia intestinalis in mice. Journal of Nutrition, v.135, n.5, p.1171-1176, 2005.

BESIRBELLIOGLU, B.A. et al. Saccharomyces boulardii and infection due to Giardia Iamblia. Scandinavian Journal of Infectious Diseases, v.38, n.6-7, p.479-481, 2006.
DALLOUL, R.A.; LILLEHOJ, H.S. Recent advances in immunomodulation and vaccination strategies against coccidiosis. Avian Diseases, v.49, n.1, p.1-8, 2005.

DALLOUL, R.A. et al. Induction of local protective immunity to Eimeria acervulina by a Lactobacillus-based probiotic. Comparative Immunolgy, Microbiology and Infectious Diseases, v.28, n.5-6, p.351-361, 2005.

DALLOUL, R.A. et al. Enhanced mucosal immunity against Eimeria acervulina in broilers fed a Lactobacillus- based probiotic. Poultry Science, v.82, n.1, p.62-66, 2003a.

DALLOUL, R.A. et al. Intestinal immunomodulation by vitamin A deficiency and Lactobacillus-based probiotic in Eimeria acervulina-infected broiler chickens. Avian Diseases, v.47, n.4, p. 1313-1320, 2003b.

DAVIS, M.E. et al. Effect of direct-fed microbial and antibiotic supplementation on gastrointestinal microflora, mucin histochemical characterization, and immune populations of weanling pigs. Livestock Science, v.108, n.1-3, p.249-253, 2007.

EDENS, F.W. An alternative for antibiotic se in poultry: probiotics. Revista Brasileira de Ciência Avícola, v.5, n.2, p.75-97. 2003.

FARIA-FILHO, D.E. et al. Probiotics for broiler chickens in Brazil: systematic review and meta-analysis. Revista Brasileira de Ciência Avícola, v.8, n.2, p.89-98, 2006.

FIORAMONTI, J. et al. . Probiotics: what are they? What are their effects on gut physiology? Best Practice \& Research. Clinical Gastroenterology, v.17, n.5, p.711-724, 2003.

FOLIGNE, B. et al. Correlation between in vitro and in vivo immunomodulatory properties of lactic acid bacteria. World Journal of Gastroenterology, v.13, n.2, p.236-243, 2007.

FOSTER, J.C. et al. Effect of Lactobacillus and Bifidobacterium on Cryptosporidium parvum oocyst viability. Food Microbiology, v.20, n.3, p.351-357, 2003.

GILL, H.S. Probiotics to enhance anti-infective defenses in the gastrointestinal tract. Best Practice \& Research Clinical Gastroenterology, v.17, n.5, p.755-773, 2003

GIONCHETTI, P. et al. Probiotics in gastroenterology. Current Opinion Gastroenterology, v.18, n.2, p.235-259, 2002.

GLASS, M.D. et al. Effects of Lactobacillus acidophilus and Lactobacillus reuteri cell-free supernatants on Cryptosporidium viability and infectivity in vitro. Food Microbiology, v.21, n.4, p.423-429, 2004

GUERRA, N.P. et al. Production of four potentially probiotic lactic acid bacteria and their evaluation as feed additives for weaned piglets. Animal Feed Science and Technology, v.134, n.1-2, p.89-107, 2007.

GUILLOT, C.C. et al. Effects of Saccharomyces boullardii in children with chronic diarrhea, especially cases due to giardiasis. Revista Mexicana de Puericultura y Pediatria, v.2, n.12, p.1-11, 1995. 
GUITARD, J. et al. Experimental study of the effects of probiotics on $C$. parvum infection in neonatal rats. Parasitology Research, v.99, n.5, p.522-527, 2006.

HARP, J.A. Parasitic infections of the gastrointestinal tract. Current Opinion in Gastroenterology, v.19 n.1, p.31-36, 2003

HARP, J.A. et al. Resistance of severe combined immunodeficient mice to infection with Cryptosporidium parvum: the importance of intestinal microflora. Infection and Immunity, v.60, n.9, p.3509-3512, 1992.

HARP, J.A. et al. Susceptibility of germfree or antibiotictreated adult mice to Cryptosporidium parvum. Infection and Immunity, v.56, n.8, p.2006-2010, 1988.

HOLZAPFEL, W.H. et al. Taxonomy and important features of probiotic microorganisms in food and nutrition. American Journal of Clinical Nutrition, v.73, n.2(suppl.), p.365-373, 2001.

HUMEN, M.A. et al. Lactobacillus johnsonii La1 antagonizes Giardia intestinalis in vivo. Infection and Immunity, v.73, n.2, p.1265-1269, 2005.

ISOLAURI, E. et al. Probiotics in the management of atopic eczema. Clinical and Experimental Allergy, v.30, n.11, p.1604-1610, 2000

IVEC, M. et al. Interactions of macrophages with probiotic bacteria lead to increased antiviral response against vesicular stomatitis virus. Antiviral Research, v.75, n.3, p.266-274, 2007.

KALLIOMÄKI, M. et al. Probiotics in primary prevention of atopic disease: a randomised placebo-controlled trial. Lancet, v.357, n.9262, p.1076-1079, 2001.

LEE, H.S. et al. Influence of Pediococcus-based probiotic on coccidiosis in broiler chickens. Poultry Science, v.86, n.1, p.63-66, 2007.

LILLY, D.M.; STILLWELL, R.H. Probiotics: growthpromoting factors produced by microorganisms. Science, v.12, n.147, p.747-748, 1965.

LIPNER, E.M. et al. Coincident filarial, intestinal helminth, and mycobacterial infection: helminths fail to influence tuberculin reactivity, but BCG influences hookworm prevalence. American Journal of Tropical Medicine and Hygiene, v.74, n.5, p.841-847, 2006.

MACK, D.R. et al. Extracellular MUC3 mucin secretion follows adherence of Lactobacillus strains to intestinal epithelial cells in vitro. Gut, v. 52, n.6, p.827-833, 2003.

MAJAMAA, H.; ISOLAURI, E. Probiotics: a novel approach in the management of food allergy. Journal of Allergy and Clinical Immunology, v.99, n.2, p.179-185, 1997.

MANSOUR-GHANAEI, F. et al. Efficacy of Saccharomyces boulardii with antibiotics in acute amoebiasis. World Journal of Gastroenterology, v.9, n.8, p.1832-1833, 2003.

MARTIN, F.P.J. et al. Transgenomic metabolic interactions in a mouse disease model: interactions of Trichinella spiralis infection with dietary Lactobacillus paracasei supplementation. Journal of Proteome Research, v.5, n.9, p.2185-2193, 2006.

MISSOTTEN, J.A.M. et al. Screening of two probiotic products for use in fermented liquid feed. Livestock Science, v.108, n.1-3, p.232-235, 2007.

OHASHI, Y. et al. Habitual intake of lactic acid bacteria and risk reduction of bladder cancer. Urologia Internationalis, v.68, n.4, p.273-280, 2002

PATURI, G. et al. Immune enhancing effects of Lactobacillus acidophilus LAFTI L10 and Lactobacillus paracasei LAFTI L26 in mice. International Journal of Food Microbiology, v.115, n.1, p.115-118, 2007.

PÉREZ, P.F. et al. Inhibition of Giardia intestinalis by extracellular factors from Lactobacilli: an in vitro study. Applied and Environmental Microbiology, v.67, n.11, p.5037-5042, 2001.

PICKERD, N.; TUTHILL, D. Resolution of cryptosporidiosis with probiotic treatment. Postgraduate Medical Journal, v.80, n.940, p.112-113, 2004.

RAFTER, J. et al. Dietary synbiotics reduce cancer risk factors in polypectomized and colon cancer patients. American Journal of Clinical Nutrition, v.85, n.2, p.488-496, 2007.

REID, G.; BRUCE, A.W. Probiotics to prevent urinary tract infections: the rationale and evidence. World Journal of Urology, v.24, n.1, p.28-32, 2006.

REID, G. et al. The rationale for probiotics in female urogenital healthcare. Medscape General Medicine, v.6, n.1, p.4956, 2004

RIGOTHIER, M.C. et al. Inhibitory activity of Saccharomyces yeasts on the adhesion of Entamoeba histolytica trophozoites to human erythrocytes in vitro. Parasitology Research , v.80, n.1, p.10-15, 1994.

RINKINEN, M. et al. Interaction between probiotic lactic acid bacteria and canine enteric pathogens: a risk factor for intestinal Enterococcus faecium colonization? Veterinary Microbiology, v 92, n.1-2, p.111-119, 2003.

SALMINEN, S.J. et al. Probiotics that modify disease risk. Journal of Nutrition, v.135, n.5, p.1294-1298, 2005.

SANDERS, M.E. Probiotics: considerations for human health. Nutrition Reviews, v.61, n.3, p.91-99, 2003.

SANTOS, J.F. et al.. O efeito da cultura de Zymomonas mobilis na infecção experimental por Schistosoma mansoni. Revista da Sociedade Brasileira de Medicina Tropical. v.37, n.6, p.502-504, 2004.

SINGER, S.M.; NASH, T.E. The role of normal flora in Giardia lamblia infections in mice. Journal of Infectious Diseases, v.181, p.1510-1512, 2000. 
SOLANO-AGUILAR, G. et al. The effect of human-derived probiotic bacteria on the intestinal function of pigs. Veterinary Parasitology, v.125, 1-2, p.47-61, 2004.

SPENCER, R.J.; CHESSON, A. The effect of Lactobacillus spp. on the attachment of enterotoxigenic Escherichia coli to isolated porcine enterocytes. Journal of Applied Bacteriology, v.77, n.2, p.215-220, 1994.

TEIXEIRA, K.M. et al. Effects of non-specific immunopotentiators in experimental Schistosoma mansoni infection. II. Corynebacterium parvum. Revista do Instituto de Medicina Tropical de São Paulo, v.38, n.5, p.359-363, 1996.

WATERS, W.R. et al. Effects of Lactobacillus reuteri on Cryptosporidium parvum infection of gnotobiotic TCR-alphadeficient mice. Journal of Eukaryotic Microbiology, v.46, n.5, p.60S-61S, 1999.
WILLIAMS, R.B. Relative virulence of a drug-resistant and a drug-sensitive strain of Eimeria acervulina a coccidium of chickens. Veterinary Parasitology, v.135, n.1, p.15-23, 2006.

WRIGHT, J.M. et al. Efficacy of antigiardial drugs. Expert Opinion on Drug Safety, v.2, n.6, p.529-541, 2003.

YAMANAKA, T. et al. Microbial colonization drives lymphocyte accumulation and differentiation in the follicle associated epithelium of Peyer's patches. Journal of Immunolology, v.170, p.816-822, 2003.

YARLETT, N. et al. Cryptosporidium parvum spermidine/ spermine N(1)-acetyltransferase exhibits different characteristics from the host enzyme. Molecular and Biochemical Parasitology, v.152, n.2, p.170-80, 2007.

ZÁRATE, G.; NADER-MACIAS, M.E. Influence of probiotic vaginal lactobacilli on in vitro adhesion of urogenital pathogens to vaginal epithelial cells. Letters in Applied Microbiology, v.43, n.2, p.174-180, 2006. 